\title{
Influence of indomethacin on the ventilatory and cerebrovascular responsiveness to hypoxia
}

\author{
Jui-Lin Fan • Keith R. Burgess • Kate N. Thomas • Karen C. Peebles • \\ Samuel J. E. Lucas • Rebekah A. I. Lucas · James D. Cotter • Philip N. Ainslie
}

Accepted: 28 September 2010/Published online: 12 October 2010

(C) Springer-Verlag 2010

\begin{abstract}
Indomethacin (INDO) has the potential to be a useful tool to explore the influence of cerebral blood flow and its responses to $\mathrm{CO}_{2}$ on ventilatory control. However, the effect of INDO on the cerebrovascular and ventilatory response to hypoxia remains unclear; therefore, we examined the effect of INDO on ventilatory and cerebrovascular sensitivity to hypoxia and hypercapnia. We measured endtidal gases, ventilation $\left(\dot{V}_{\mathrm{E}}\right)$, and middle cerebral artery velocity (MCAv) before and $90 \mathrm{~min}$ following INDO (100 mg) in 12 healthy participants at rest and during hyperoxic hypercapnia and isocapnic hypoxia. Following INDO, resting $\dot{V}_{\mathrm{E}}$ and end-tidal gases were unaltered $(P>0.05)$, whilst MCAv was lowered by $25 \pm 19 \%$
\end{abstract}

Communicated by Susan Ward.

J.-L. Fan · K. N. Thomas - K. C. Peebles

S. J. E. Lucas - R. A. I. Lucas

Department of Physiology, Otago School of Medical Science,

University of Otago, Dunedin, New Zealand

K. R. Burgess

Department of Medicine, University of Sydney,

Sydney, NSW, Australia

S. J. E. Lucas - R. A. I. Lucas - J. D. Cotter

School of Physical Education,

University of Otago, Dunedin, New Zealand

P. N. Ainslie

Department of Health and Human Kinetics, Faculty of Health and Social Development, University of British Columbia

Okanagan, Kelowna, Canada

J.-L. Fan $(\bowtie)$

Institute of Movement Sciences and Sports Medicine,

University of Geneva, Geneva, Switzerland

e-mail: Jui-Lin.Fan@unige.ch
$(P<0.001)$. INDO ingestion reduced $\mathrm{MCAv}-\mathrm{CO}_{2}$ reactivity by $46 \pm 29 \%\left(2.9 \pm 0.9\right.$ vs. $1.7 \pm 0.9 \mathrm{~cm} \mathrm{~s}^{-1}$ $\left.\mathrm{mmHg}^{-1} ; P<0.001\right)$ and enhanced the $\dot{V}_{\mathrm{E}}-\mathrm{CO}_{2}$ sensitivity by $0.5 \pm 0.5 \mathrm{~L} \mathrm{~min}^{-1} \mathrm{mmHg}^{-1}(1.9 \pm 1.5$ vs. $2.3 \pm$ $\left.1.6 \mathrm{~L} \mathrm{~min}^{-1} \mathrm{mmHg}^{-1} ; \quad P<0.05\right)$. No changes were observed in either the MCAv or $\dot{V}_{\mathrm{E}}$ responsiveness to isocapnic hypoxia following INDO ingestion $(P>0.05)$. These findings indicate that INDO does not alter cerebrovascular and ventilatory responsiveness to hypoxia, indicating a preserved peripheral chemoreflex in response to this pharmacological agent.

Keywords Indomethacin - Cerebral blood flow . Chemoreflex

\section{Introduction}

The net $\left[\mathrm{H}^{+}\right]$in the environment of central chemoreceptors is dependent on the rate of $\mathrm{CO}_{2}$ production and the rate of $\mathrm{CO}_{2}$ washout in the brain. The former is determined by cerebral metabolism, whilst the latter is regulated by the cerebral blood flow (CBF) response to changes in the partial pressure of arterial $\mathrm{CO}_{2}\left(P_{\mathrm{a}} \mathrm{CO}_{2}\right)$ in the braintermed cerebrovascular $\mathrm{CO}_{2}$ reactivity. For example, reduced resting $\mathrm{CBF}$ and blunted cerebrovascular $\mathrm{CO}_{2}$ reactivity have been shown to increase the jugular venous $\mathrm{PCO}_{2}$ (Chapman et al. 1979a), whilst an increase in CBF lowers brain tissue $\mathrm{PCO}_{2}$ (Fencl 1986). Accordingly, it has been proposed that $\mathrm{CBF}$ and cerebrovascular $\mathrm{CO}_{2}$ reactivity may help regulate central (i.e. brain) $\mathrm{pH}$, and thus affects the most important input to respiratory drive (central chemoreceptor stimulus) (Chapman et al. 1979a; Hohimer et al. 1985; Xie et al. 2006). 
Chapman et al. (1979a) previously reported that, in unanaesthetised goats, a 30\% reduction in $\mathrm{CBF}$ and cerebrovascular $\mathrm{CO}_{2}$ reactivity (via carotid clamping) elevates jugular venous $\mathrm{PCO}_{2}$ and augments the ventilatory response to hyperoxic rebreathing, but not to transient hypoxia. Since hyperoxia is known to silence the peripheral chemoreceptor activity (Cunningham et al. 1963; Gardner 1980; Mohan and Duffin 1997), Chapman et al. (1979a) proposed that a blunted cerebrovascular $\mathrm{CO}_{2}$ reactivity, by attenuating the washout of $\mathrm{H}^{+}$from the brain, selectively enhances the central chemoreflex without altering the peripheral chemoreflex. In the same study, they also found that further reductions in $\mathrm{CBF}(50 \%)$ and near abolishment of cerebrovascular $\mathrm{CO}_{2}$ reactivity depresses both the central and peripheral chemoreflexes, presumably due to the hypoxic depression of respiratory neurons associated with severe cerebral ischaemia (Chapman et al. 1979b). In addition, Nishimura et al. (1987) provided evidence that the cerebrovascular responsiveness to hypoxia modulates the ventilatory responsiveness to hypoxia via $\mathrm{H}^{+}$washout from the brain, thereby attenuating the central drive, at least during moderate hypoxic exposure. Taken together, these findings support the role of $\mathrm{CBF}$ and its responses to $\mathrm{CO}_{2}$ and $\mathrm{O}_{2}$ in the control of breathing.

Indomethacin (INDO) is a potent reversible cyclooxygenase inhibitor, which has been shown to impair the cerebral vessels' ability to dilate in response to potent vasodilatory stimulus such as hypercapnia and iloprost (a prostacyclin receptor agonist) (Parfenova et al. 1994; Parfenova et al. 1995b). Accordingly, the authors concluded that INDO lowers $\mathrm{CBF}$ and cerebrovascular $\mathrm{CO}_{2}$ reactivity by selective inhibition of prostaglandin $\mathrm{H}$ synthase and prostacyclin receptor-mediated responses (Parfenova et al. 1995b). Moreover, numerous studies have found that INDO lowers $\mathrm{CBF}$ and attenuates the cerebrovascular reactivity to $\mathrm{CO}_{2}$ (Bruhn et al. 2001; Eriksson et al. 1983; Ivancev et al. 2009; Kastrup et al. 1999; Markus et al. 1994; St Lawrence et al. 2002; Wennmalm et al. 1983) without concomitant changes in cerebral metabolic rate (Hohimer et al. 1985; Kraaier et al. 1992) or plasma catecholamines (Green et al. 1987; Staessen et al. 1984; Wennmalm et al. 1984). Recently, it had been demonstrated that INDO (100 mg) enhances the central chemoreflex (Fan et al. 2010; Xie et al. 2006), increases the propensity for apnoea during sleep in healthy humans (Xie et al. 2009) and exacerbates the severity of obstructive sleep apnoea (Burgess et al. 2010). These changes in ventilatory control were attributed to the INDO-induced reduction in cerebrovascular $\mathrm{CO}_{2}$ reactivity and associated reduction in $\mathrm{H}^{+}$washout, resulting in an increase in central chemoreceptor activation (Hohimer et al. 1985). Despite the numerous studies on the central chemoreflex, however, the effect of INDO on peripheral chemoreflex in humans is yet to be examined.
Animal studies have reported an enhanced carotid body chemosensitivity to hypoxia and hypercapnia with INDO, whilst no changes were observed under normoxic and eucapnic conditions (Gomez-Nino et al. 1992, 1994). In contrast, other studies have found that, since bilateral carotid section failed to abolish INDO-induced increases in respiratory movement or $\dot{V}_{\mathrm{E}}$, the effect of INDO on $\dot{V}_{\mathrm{E}}$ is unlikely to be mediated by the carotid bodies (Jansen et al. 1984; McQueen and Belmonte 1974). In healthy resting humans, Xie et al. (2006) found that oral INDO caused a $37 \%$ reduction in cerebrovascular $\mathrm{CO}_{2}$ reactivity and a 40-60\% increase in the $\dot{V}_{\mathrm{E}}$ responsiveness to steady-state hyperoxic hypercapnia and normoxic hypercapnia. Since no differences were observed between the hyperoxic and normoxic conditions, it was proposed that the observed increase in ventilatory sensitivity to $\mathrm{CO}_{2}$ following INDO was primarily due to an augmented central chemoreceptor activation via reduced $\mathrm{H}^{+}$washout in the brainstem, rather than any concurrent changes in peripheral chemoreflex (Xie et al. 2006). However, since the nature of the interactions between central and peripheral chemoreceptors is yet unclear (Blain et al. 2009; Dahan et al. 2008; Day and Wilson 2009), the findings by Xie et al. (2006) should be interpreted with caution. As such, no studies have yet examined the effect of INDO on the ventilatory responsiveness to hypoxia per se. Likewise, previous animal studies have demonstrated that INDO blunts the $\mathrm{CBF}$ response to hypoxia (cerebrovascular $\mathrm{O}_{2}$ reactivity) in a dose-dependent manner (Coyle et al. 1993, 1995). However, the effect of INDO on the cerebrovascular reactivity to hypoxia has not been previously examined in humans. Since cerebrovascular hypoxic reactivity plays an important role in modulating hypoxic ventilatory response (Nishimura et al. 1987), INDO-induced changes in the cerebrovascular $\mathrm{O}_{2}$ reactivity may account, in part, for any potential alterations in the peripheral chemoreflex.

The purpose of this study was to examine the effect of INDO on the CBF and $\dot{V}_{\mathrm{E}}$ response to hypoxia in humans. We examined the hypothesis that INDO-induced reduction in cerebrovascular $\mathrm{CO}_{2}$ reactivity would augment $\dot{V}_{\mathrm{E}}$ responsiveness to $\mathrm{CO}_{2}$ without any concurrent alterations in the cerebrovascular and ventilatory responsiveness to hypoxia.

\section{Methods}

\section{Participants}

Twelve adults ( 8 male and 4 female) with a mean age of $30 \pm 10$ years (mean \pm SD), and body mass index of $23 \pm 2 \mathrm{~kg} \mathrm{~m}^{-2}$ participated in this study. Participants were 
non-smokers, had no previous history of cardiovascular, cerebrovascular or respiratory diseases and were not taking any medications. All participants were informed regarding the purposes and procedures of this study, and informed consent was given prior to participation. The study was approved by the Lower South Regional Ethics Committee of Otago and conformed to the standards set by the Declaration of Helsinki.

\section{Experimental design}

The participants were required to visit the laboratory on two occasions. After a full familiarisation with the experimental procedures outlined below (visit one), participants underwent one experimental trial (INDO). To account for the time course effect, 7 of the 12 participant also underwent a placebo trial (randomised order) separated by at least 7 days. Both the INDO $(100 \mathrm{mg})$ and placebo trials were administered in identical-looking capsules and ingested with $20 \mathrm{~mL}$ of antacid (Maalox). Before each experimental session, participants were informed to abstain from exercise and alcohol for $24 \mathrm{~h}$, caffeine for $12 \mathrm{~h}$ and a heavy meal for $4 \mathrm{~h}$ prior. Experiments were conducted at the same time of day for each participant to reduce the known influence of circadian rhythm on the key cardiorespiratory and cerebrovascular variables (Ainslie and Duffin 2009).

All experiments were performed with participants semirecumbent and with temperate controlled at $22^{\circ} \mathrm{C}$. Following 10-15 min of quiet rest, each experimental testing session comprised: (a) instrumentation; (b) hyperoxic hypercapnia and isocapnic hypoxia; (c) INDO/placebo administration; (d) 90-min rest, and (e) repeat testing of (a) and (b). The order of the hyperoxic hypercapnia and isocapnic hypoxia was randomised and full recovery $(5 \mathrm{~min})$ was permitted between each trial to restore end-tidal gases to baseline resting values.

\section{Hyperoxic hypercapnia}

The participants breathed through a leak-free respiratory mask (Hans-Rudolph 8980, Kansas City, MO) attached to a one-way non-rebreathing valve (Hans-Rudolph 2700). The inspiratory line contained a Y-valve, which allowed switching from room air to a 200-L Douglas bag containing $7 \% \mathrm{CO}_{2}$ and $93 \% \mathrm{O}_{2}$. The steady-state test began with 2 min of baseline room air breathing, before switching onto the Douglas bag for 4 min.

\section{Isocapnic hypoxia}

Participants wore a nose clip and breathed through a mouthpiece connected to a Y-valve allowing switching from room air to a circuit consisting of a 6-L rebreathing bag and a soda lime reservoir. Isocapnic hypoxia began with 2-min baseline room air breathing, before participants switched to the rebreathing circuit at the end of inspiration. Isocapnic hypoxia was terminated when: (1) the participant's peripheral $\mathrm{O}_{2}$ saturation $\left(\mathrm{S}_{\mathrm{p}} \mathrm{O}_{2}\right)$ reached $80 \%$; (2) the participant's partial pressure of end-tidal $\mathrm{O}_{2} \quad\left(P_{\mathrm{ET}} \mathrm{O}_{2}\right)$ reached $45 \mathrm{mmHg}$; (3) the participant's $\dot{V}_{\mathrm{E}}$ exceeded $100 \mathrm{~L} \mathrm{~min}^{-1}$; or (4) the participant reached the end of his tolerance.

\section{Measurements}

Respiratory variables

Pulmonary $\dot{V}_{\mathrm{E}}$ and its components, tidal volume $\left(V_{\mathrm{T}}\right)$ and breathing frequency $(f)$, were measured using a heated pneumotachograph (Hans-Rudolph HR800) and expressed in units adjusted to BTPS. The fractional changes in inspired and expired $\mathrm{O}_{2}$ and $\mathrm{CO}_{2}$ were used to calculate partial pressure of end-tidal $\mathrm{O}_{2}$ and $\mathrm{CO}_{2}\left(P_{\mathrm{ET}} \mathrm{CO}_{2}\right)$ with fast responding gas analysers (AEI Technologies, Pittsburgh, PA). The pneumotachograph was calibrated using a 3-L syringe (Hans-Rudolph 2700, Kansas City, MO) and the gas analysers were calibrated using known concentrations of $\mathrm{O}_{2}$ and $\mathrm{CO}_{2}$ prior to each testing session.

\section{Cerebrovascular and cardiovascular variables}

Middle cerebral artery velocity (MCAv, an index of CBF) was measured in the right middle cerebral artery using a 2-MHz pulsed Doppler ultrasound system (DWL Doppler, Sterling, VA). The Doppler ultrasound probe was positioned over the right temporal window and held in place with an adjustable plastic headband. The signals were obtained using search techniques described elsewhere (Aaslid et al. 1982). Frontal cortical cerebral oxygenation was measured in seven participants using near-infrared spectroscopy (NIRS) (NIRO-200; Hamamatsu Photonics; Hamamatsu, Japan). A probe holder containing an emission probe and detection probe was attached at the right side of the forehead with a distance of $5 \mathrm{~cm}$ between the probes. The methodology of this system has been described previously (Al-Rawi et al. 2001; Nollert et al. 1995). Heart rate (HR) was determined using a three-lead ECG. Beatto-beat mean arterial blood pressure (MAP) was monitored using finger photoplethysmography (Finometer, TPD Biomedical Instrumentation). To ensure accurate measurements of MAP, right arm manual blood pressure measurements by auscultation were also made periodically to check and validate the automated recordings. 
Cerebrovascular conductance index (CVCi) was estimated by dividing mean MCAv by MAP within each breath cycle to reveal intrinsic vascular responses to $\mathrm{CO}_{2}$ (Claassen et al. 2007). Peripheral $\mathrm{O}_{2}$ saturation $\left(S_{\mathrm{p}} \mathrm{O}_{2}\right)$ was obtained using a finger pulse oximeter.

Data analysis

\section{Hyperoxic hypercapnia}

$\dot{V}_{\mathrm{E}}, \mathrm{MCAv}$ and CVCi responsiveness to $\mathrm{CO}_{2}$ was estimated from the slope of the mean value of each dependant variable in the final minute of baseline and steady-state hyperoxic hypercapnic breathing. Steady-state hypocapnic cerebrovascular reactivity was estimated from the slope of the mean MCAv in the final minute of baseline and voluntary hyperventilation prior to the rebreathing. It should be acknowledged that the steady-state determination of ventilatory $\mathrm{CO}_{2}$ sensitivity is restricted to the number of data points used in the analysis (Mohan et al. 1999; Pandit et al. 2007). However, the steady-state $\dot{V}_{\mathrm{E}}-\mathrm{CO}_{2}$ sensitivities (control and INDO) observed in the present study (Fig. 1) were comparable to those reported by Xie et al. (2006) who used four steady-state data points (baseline, 2, 4 and 6\% $\mathrm{CO}_{2}$ ), thereby supporting the use of two data points in estimating steady-state ventilatory $\mathrm{CO}_{2}$ sensitivity in the present study.

\section{Isocapnic hypoxia}

To express the $\dot{V}_{\mathrm{E}}$ and MCAv changes as a linear function of the hypoxic stimulus during isocapnic hypoxia, $P_{\mathrm{ET}} \mathrm{O}_{2}$ was converted to a calculated arterial $\mathrm{O}_{2}$ saturation $\left(\mathrm{S}_{\mathrm{c}} \mathrm{O}_{2}\right)$ using the equation (Severinghaus 1979):

$S_{\mathrm{c}} \mathrm{O}_{2}=\left[\left(P_{\mathrm{ET}} \mathrm{O}_{2}^{3}+150 P_{\mathrm{ET}} \mathrm{O}_{2}\right)^{-1} \times 23,400+1\right]^{-1} \times 100$

where $S_{\mathrm{c}} \mathrm{O}_{2}$ is a percentage and $P_{\mathrm{ET}} \mathrm{O}_{2}$ is in $\mathrm{mmHg}$.

Changes in $\dot{V}_{\mathrm{E}}$ and MCAv were then subsequently plotted against $S_{\mathrm{c}} \mathrm{O}_{2}$ using linear regression to obtain the respiratory and cerebrovascular responsiveness to hypoxia.

Statistical analysis

To assess the effect of INDO on resting variables, ventilatory and cerebrovascular changes during hyperoxic hypercapnia and isocapnic hypoxia, we used paired $t$ test with $\alpha$-level of $P<0.05$ (SPSS version 17.0, SPSS, Chicago, IL). Likewise, to assess the effect of placebo on resting variables, ventilatory and cerebrovascular changes during hyperoxic hypercapnia and isocapnic hypoxia, we used paired $t$ test with $\alpha$-level of $P<0.05$.

\section{Results}

All 12 participants completed the placebo and INDO trial with the hyperoxic hypercapnia and isocapnic hypoxia.

Baseline

Indomethacin ingestion reduced both MCAv and CVCi by $25 \pm 19$ and $31 \pm 22 \%$, respectively, from baseline $(P<0.001$; Table 1), whilst no changes were observed following placebo ingestion $(P>0.05$; Table 1$)$. In contrast, placebo ingestion increased cerebral oxygenation by $4.7 \pm 4.4 \%(P<0.05$; Table 1$)$, whilst no changes were observed with INDO $(P>0.05)$. Neither placebo nor INDO altered any resting respiratory variables $(P>0.05$; Table 1). INDO lowered resting $\mathrm{HR}$ by $8 \pm 6 \mathrm{~b} \mathrm{~min}^{-1}$ $(P<0.001)$, whilst MAP remained unchanged $(P>0.05$; Table 1). Similarly, placebo lowered resting $H R$ by $5 \pm 4 \mathrm{~b} \mathrm{~min}^{-1}(P<0.01)$, whilst MAP was unchanged $(P>0.05$; Table 1).

Cerebrovascular and ventilatory responsiveness to hypercapnia and hypoxia

During the hyperoxic hypercapnia, INDO lowered the MCAv- $\mathrm{CO}_{2}$ reactivity by $46 \pm 29 \% \quad(2.9 \pm 0.9$ versus $1.7 \pm 0.9 \mathrm{~cm} \mathrm{~s}^{-1} \mathrm{mmHg}^{-1} ; P<0.001$; Fig. 1) and increased the $\dot{V}_{\mathrm{E}}-\mathrm{CO}_{2}$ sensitivity by $0.5 \pm 0.5 \mathrm{~L} \mathrm{~min}^{-1}$ $\mathrm{mmHg}^{-1} \quad\left(1.9 \pm 1.5\right.$ vs. $2.3 \pm 1.6 \mathrm{~L} \mathrm{~min}^{-1} \mathrm{mmHg}^{-1}$; $P<0.01)$, whilst no changes were observed with placebo $(P>0.05)$. No differences were observed in either the MCAv- $S_{\mathrm{c}} \mathrm{O}_{2}$ reactivity or $\dot{V}_{\mathrm{E}}-S_{\mathrm{c}} \mathrm{O}_{2}$ sensitivity during isocapnic hypoxia following either placebo or INDO ingestion $(P>0.05$; Fig. 2).

\section{Discussion}

The major findings from the present study are that INDO selectively blunts the cerebrovascular $\mathrm{CO}_{2}$ reactivity and enhances the ventilatory $\mathrm{CO}_{2}$ sensitivity without affecting either the cerebrovascular or the ventilatory responsiveness to hypoxia.

Methodological considerations

\section{Indomethacin}

Indomethacin was used in this study as a pharmacological means to reduce cerebrovascular $\mathrm{CO}_{2}$ reactivity in healthy resting humans without concomitant changes in cerebral metabolic rate (Hohimer et al. 1985; Kraaier et al. 1992) or plasma catecholamine concentrations (Green et al. 1987; 
Fig. 1 The cerebrovascular and ventilatory responsiveness to $\mathrm{CO}_{2}$ during hyperoxic hypercapnia before and following INDO. a Individual slopes; b group data (mean $\pm \mathrm{SD}$ ). Cerebrovascular $\mathrm{CO}_{2}$ reactivity (MCAv- $\mathrm{CO}_{2}$ reactivity); ventilatory $\mathrm{CO}_{2}$ sensitivity ( $\dot{V}_{\mathrm{E}}-\mathrm{CO}_{2}$ sensitivity). Indomethacin ingestion lowered the $\mathrm{MCAv}-\mathrm{CO}_{2}$ slope and enhanced $\dot{V}_{\mathrm{E}}-\mathrm{CO}_{2}$ sensitivity. $* *$ Different from control $(P<0.01)$; ***different from control $(P<0.001)$
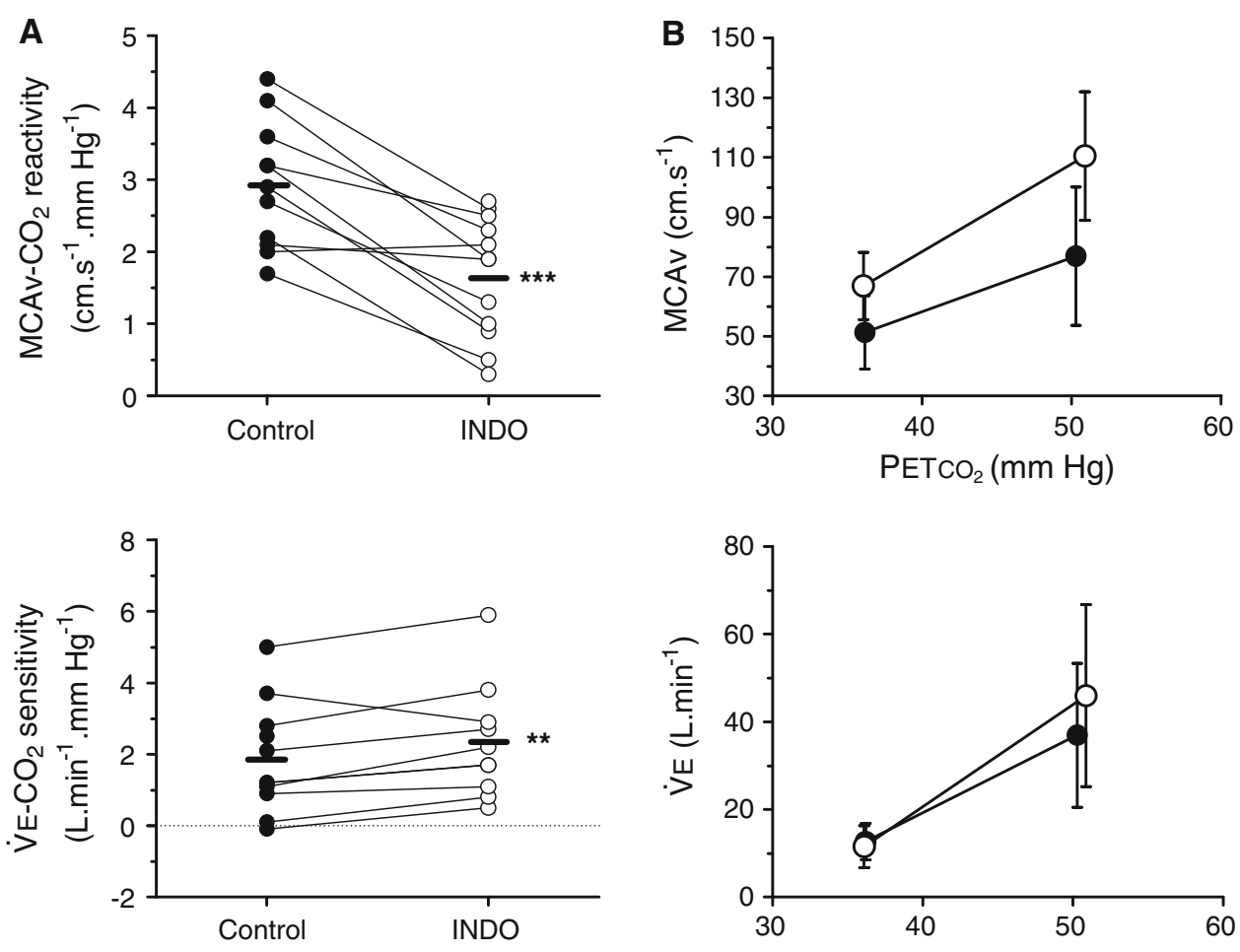

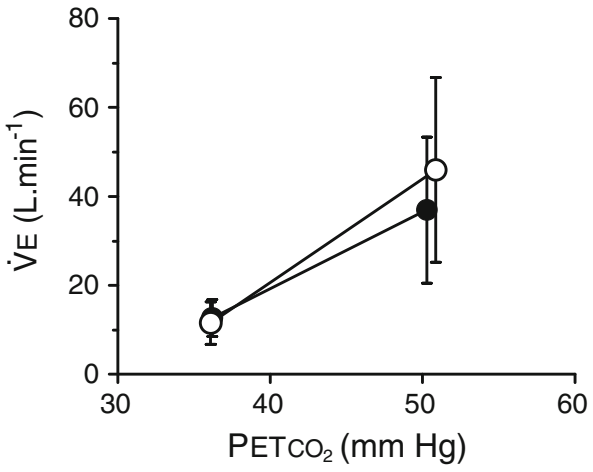

Table 1 Baseline cerebrovascular, respiratory and arterial blood gas variables before and after indomethacin

\begin{tabular}{|c|c|c|}
\hline & Control & INDO \\
\hline \multicolumn{3}{|l|}{ Cerebrovascular } \\
\hline $\operatorname{MCAv}\left(\mathrm{cm} \mathrm{s}^{-1}\right)$ & $70 \pm 10$ & $53 \pm 15^{* * *}$ \\
\hline $\mathrm{CVCi}\left(\mathrm{cm} \mathrm{s}^{-1} \mathrm{mmHg}^{-1}\right)$ & $0.86 \pm 0.18$ & $0.58 \pm 0.18^{* * *}$ \\
\hline TOI $(\%)$ & $71.7 \pm 2.2$ & $68.4 \pm 3.7$ \\
\hline \multicolumn{3}{|l|}{ Respiratory } \\
\hline$\dot{V}_{\mathrm{E}}\left(\mathrm{L} \min ^{-1}\right)$ & $12.7 \pm 3.5$ & $12.7 \pm 2.9$ \\
\hline$f$ (breaths $\min ^{-1}$ ) & $16 \pm 4$ & $15 \pm 3$ \\
\hline$V_{\mathrm{T}}(\mathrm{L})$ & $0.8 \pm 0.4$ & $0.9 \pm 0.2$ \\
\hline$P_{\mathrm{ET}} \mathrm{CO}_{2}(\mathrm{mmHg})$ & $39 \pm 5$ & $39 \pm 4$ \\
\hline$P_{\mathrm{ET}} \mathrm{O}_{2}(\mathrm{mmHg})$ & $107 \pm 5$ & $106 \pm 5$ \\
\hline \multicolumn{3}{|l|}{ Cardiovascular } \\
\hline $\operatorname{HR}\left(\mathrm{b} \min ^{-1}\right)$ & $67 \pm 10$ & $60 \pm 7 * * *$ \\
\hline MAP (mmHg) & $84 \pm 14$ & $92 \pm 13$ \\
\hline
\end{tabular}

Values are means $\pm \mathrm{SD}$

*** Different from control $(P<0.001)$

Staessen et al. 1984; Wennmalm et al. 1984). Studies have shown that the peak effect of INDO $(100 \mathrm{mg})$ on reducing MCAv occurs at $\sim 90 \mathrm{~min}$ and persists for $>4 \mathrm{~h}$ following ingestion (Markus et al. 1994; Xie et al. 2006). It is therefore reasonable to assume that, in the present study, both MCAv and the cerebrovascular $\mathrm{CO}_{2}$ reactivity would be significantly attenuated for the duration of the experimental trials following INDO ingestion (i.e. data were collected between $\sim 90$ and $150 \mathrm{~min}$ following ingestion).

Indomethacin is one of many commonly used antiinflammatory non-steroids (e.g. aspirin, ibuprofen, naproxen, sulindac), which inhibit prostaglandin synthesis by reversible inhibition of fatty acid cyclooxygenase, an important catalyst in the transformation of arachidonic acid to prostaglandins. Parfenova et al. (1994, 1995b) found, in newborn pigs, the normal increases in pial arteriolar diameter and cortical cerebrospinal cAMP with either iloprost (a prostacyclin receptor agonist) or hypercapnia were abolished or severely attenuated following INDO; also, the cerebrovascular response to isoproterenol $(\beta$-adrenoreceptor agonist) was unaffected. Since shortterm exposure to hypercapnia elevates cAMP in the vascular smooth muscles both directly and indirectly via prostaglandin-mediated endothelial pathways, resulting in cerebrovascular dilation (Hsu et al. 1993; Parfenova and Leffler 1996; Parfenova et al. 1994), such findings indicate that INDO attenuates normal cerebrovascular $\mathrm{CO}_{2}$ reactivity via selective inhibition of both prostaglandin $\mathrm{H}$ synthase and prostacyclin receptor-mediated responses (Parfenova et al. 1995a, b; Wagerle and Degiulio 1994). In support of this, Pickard et al. (1980) found the INDOinduced reduction in cerebrovascular $\mathrm{CO}_{2}$ reactivity was reversed with intracarotid prostacyclin infusion in baboons. In addition, INDO has been shown to partially 
Fig. 2 The cerebrovascular and ventilatory responsiveness to calculated arterial $\mathrm{O}_{2}$ saturation during isocapnic hypoxia before and following INDO.

a Individual slopes; $\mathbf{b}$ group data (mean $\pm \mathrm{SD}$ ). Cerebrovascular $\mathrm{O}_{2}$ reactivity (MCAv- $\mathrm{S}_{\mathrm{c}} \mathrm{O}_{2}$ reactivity); ventilatory $\mathrm{O}_{2}$ sensitivity $\left(\dot{V}_{\mathrm{E}}-\mathrm{S}_{\mathrm{c}} \mathrm{O}_{2}\right.$ sensitivity). Indomethacin did not alter either the cerebrovascular or the ventilatory responsiveness to hypoxia
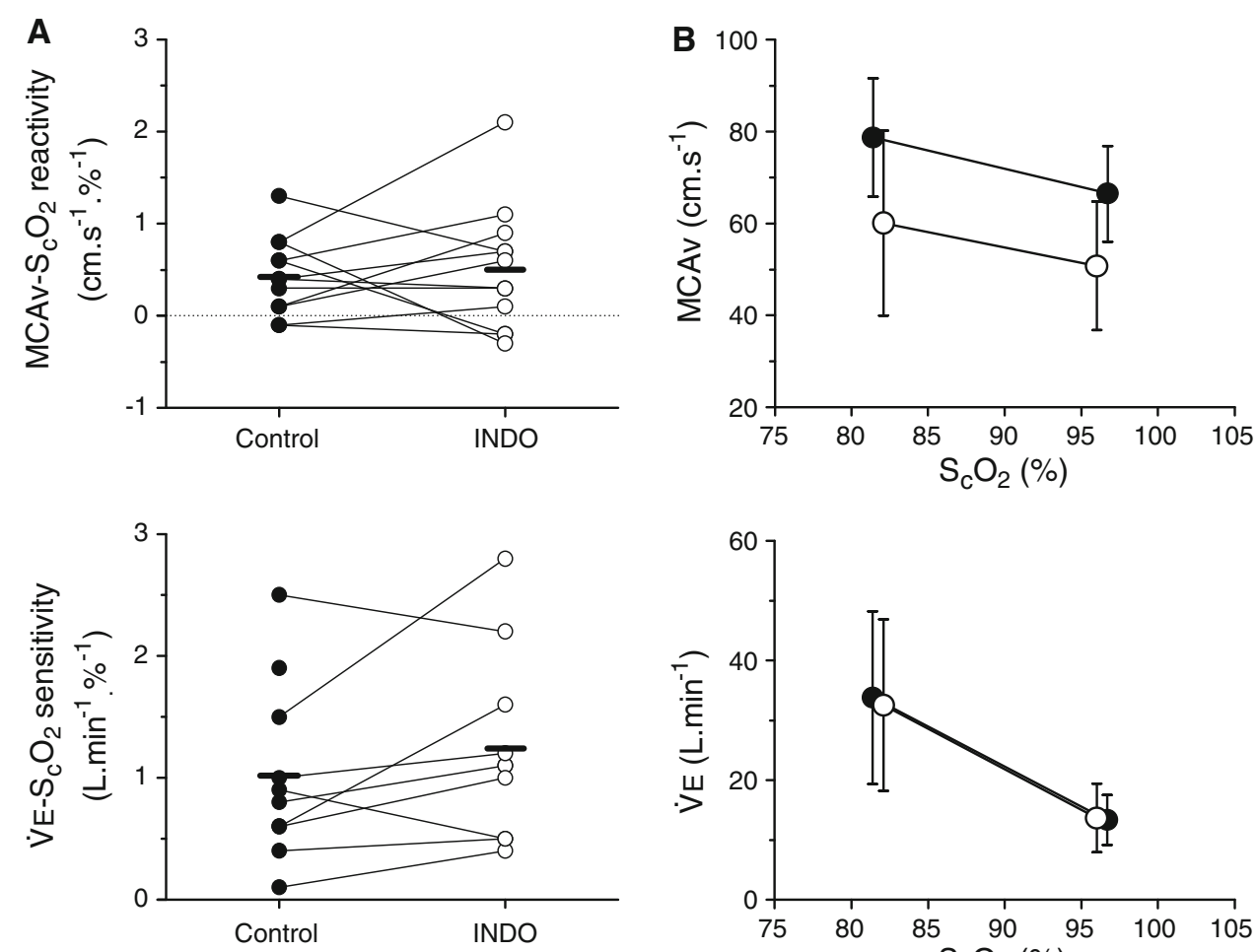

inhibit lipopolysaccharide-induced dilation in the cerebrovasculature (Brian et al. 1998).

Interestingly, studies have only reported reductions in resting $\mathrm{CBF}$ and cerebrovascular responsiveness to $\mathrm{CO}_{2}$ following oral ingestion of INDO, but not aspirin, sulindac, naproxen or ibuprofen (Eriksson et al. 1983; Markus et al. 1994; Parfenova et al. 1995b; Wagerle and Degiulio 1994). This lack of change in basal $\mathrm{CBF}$ and cerebrovascular $\mathrm{CO}_{2}$ reactivity has led to speculations that these other non-steroidal anti-inflammatory drugs may not cross the bloodbrain barrier sufficiently to alter cerebrovascular function (Eriksson et al. 1983) or are less effective in the inhibition of prostanoid-induced cAMP formation (Parfenova et al. 1995b). In support of this, both aspirin and ibuprofen failed to inhibit the pial arteriolar dilation response to hypercapnia despite being effective in inhibiting prostanoids synthesis (Parfenova et al. 1995b; Wagerle and Degiulio 1994). Moreover, Parfenova et al. (1995b) found, in contrast to INDO (5 $\mathrm{mg} \mathrm{kg}^{-1}$ i.v.), aspirin (50 $\mathrm{mg} \mathrm{kg}^{-1}$ i.v.) failed to attenuate the prostacyclin receptor-mediated increase in cAMP formation by the microvascular smooth muscle and endothelial cells. The authors speculated that the inhibition of prostanoids production is necessary, but not sufficient, to block the prostanoids-induced cerebrovascular response to hypercapnia. Instead, inhibition of both cortical prostanoids synthase and prostacyclin receptor activation may be needed to blunt the cerebrovascular $\mathrm{CO}_{2}$ reactivity. Alternatively, it is possible that INDO may alter cerebrovascular function via non-prostaglandin pathways, such as inhibition of histamine release (Konig et al. 1987), calcium channel blockade (Northover 1977), potentiation of lipoxygenase pathway (Docherty and Wilson 1987), modification of extracellular $\mathrm{pH}$ (Wang et al. 1993), INDO's scavenging effect on inhibition of superoxide generation (Pourcyrous et al. 1993), or via increases in endothelin-1 (Therkelsen et al. 1994). Most noteworthy is the finding by Wang et al. (1993), which showed that INDO abolished the acetazolamide-induced increase in CBF. Since acetazolamide is known to increase cerebral acidosis via a carbonic anhydrase inhibition and associated increase in $\mathrm{CO}_{2}$ retention, the authors conclude that INDO acts to lower the cerebrovascular $\mathrm{CO}_{2}$ reactivity by a non-prostaglandin-mediated mechanism that directly interferes with the regulation of $\mathrm{CBF}$ and cerebrovascular tone mediated by an increase in extracellular $\mathrm{pH}$. However, Hohimer et al. (1985) found INDO-induced reduction in CBF increased the sagittal vein $\left[\mathrm{H}^{+}\right]$. Therefore, it seems unlikely that INDO directly alters cerebral $\mathrm{pH}$. Moreover, an increase in cerebral $\mathrm{pH}$ would attenuate, rather than augment, the ventilatory response to hyperoxic hypercapnia.

\section{Assessment of $C B F$}

In this study, transcranial Doppler ultrasound was used to measure the MCAv as an index of global CBF 
responsiveness to $\mathrm{CO}_{2}$. Numerous studies have provided evidence, which support the validity of MCAv as an index of regional CBF (Bishop et al. 1986; Nuttall et al. 1996; Peebles et al. 2008; Serrador et al. 2000; ter Minassian et al. 1998; Valdueza et al. 1997). Moreover, studies have shown that the MCA diameter is relatively unchanged in the range of 23-60 mmHg for $P_{\mathrm{a}} \mathrm{O}_{2}$ (Giller et al. 1993; Serrador et al. 2000; Valdueza et al. 1997). However, evidence of unchanged MCA diameter during hypoxia is still lacking. Nevertheless, it is noteworthy that the observed MCAv response during isocapnic hypoxia was comparable to findings by Noth et al. (2008), who have previously assessed the CBF response to isocapnic hypoxia using MRI (Noth et al. 2008). Importantly, consistent with our observations (Fig. 2), these authors also reported high intra-subject variability in CBF response to hypoxia (Noth et al. 2008). Collectively, these findings support the use of MCAv as a valid measure of CBF.

Influence of indomethacin on cerebrovascular reactivity to $\mathrm{CO}_{2}$ and $\mathrm{O}_{2}$

Numerous human studies using transcranial Doppler ultrasound (Ivancev et al. 2009; Markus et al. 1994; Xie et al. 2006), MRI (Bruhn et al. 2001; St Lawrence et al. 2002), ${ }^{133}$ Xe method (Jensen et al. 1996) and $\mathrm{N}_{2} \mathrm{O}$ washout method (Eriksson et al. 1983; Wennmalm et al. 1983) have reported that INDO reduces basal CBF by $25-35 \%$ and cerebrovascular $\mathrm{CO}_{2}$ reactivity by $50-60 \%$. Consistent with these reports, in the present study, INDO reduced resting MCAv by $25 \%$ and blunted cerebrovascular $\mathrm{CO}_{2}$ reactivity by $46 \%$ during steady-state hyperoxic hypercapnia (Fig. 1). In contrast, Pickles et al. (1984) reported a reduced basal $\mathrm{CBF}$ without any concurrent changes in cerebrovascular $\mathrm{CO}_{2}$ reactivity in six participants following 2 days of INDO oral administration $\left(100 \mathrm{mg} \mathrm{day}^{-1}\right)$. However, in that study, participants were given $50 \mathrm{mg}$ of INDO the morning of the experiment, whilst the present and other previous studies (Bruhn et al. 2001; Eriksson et al. 1983; Fan et al. 2010; Ivancev et al. 2009; Markus et al. 1994; St Lawrence et al. 2002; Wennmalm et al. 1983; Xie et al. 2006, 2009) have assessed the effect of INDO on the cerebrovascular $\mathrm{CO}_{2}$ reactivity following a single larger dose of INDO $(100 \mathrm{mg}) 90 \mathrm{~min}$ prior to measurement. Accordingly, these methodological differences make it difficult to compare the findings of the Pickles et al. (1984) study.

Nishimura et al. (1987) have previously found a reduction in the arterial-to-internal venous jugular $\mathrm{PCO}_{2}$ difference during 5-15 min of hypoxic exposure in healthy humans. From this observation, they concluded that hypoxia-induced increases in CBF would serve to increase the $\mathrm{H}^{+}$washout from the brain, thereby modulating the ventilatory drive during transient hypoxia. Importantly, these findings highlight the role of cerebrovascular reactivity to hypoxia in the modulation of hypoxic ventilatory response. The effect of INDO on the control of hypoxiainduced vasodilation in the cerebrovasculature has not been examined in humans. Most (Armstead 2000; Coyle et al. 1993, 1995; Isozumi et al. 1994; Leffler and Parfenova 1997; Mollace et al. 1997; van Bel et al. 1997), but not all (McCalden et al. 1984), animal studies have reported a reduced cerebrovascular responsiveness to hypoxia with INDO_-presumably due to the inhibition of prostaglandin production. Coyle et al. $(1993,1995)$ provided evidence to indicate that INDO attenuates hypoxia-induced cerebral vasodilation in a dose-dependent manner. They reported a reduction in CBF with a high dosage of INDO $\left(5 \mathrm{mg} \mathrm{kg}^{-1}\right)$ in pigs, whilst no changes were observed with low dosage $\left(0.3 \mathrm{mg} \mathrm{kg}^{-1}\right)$. In the present study, INDO $(\sim 1.4 \mathrm{mg}$ $\mathrm{kg}^{-1}$ ) did not alter cerebrovascular responsiveness to isocapnic hypoxia (Fig. 2). Therefore, it seems reasonable to assume that the physiological dosage of INDO used in the present study was insufficient to cause any alterations in the cerebrovascular responsiveness to hypoxia.

Effect of indomethacin on ventilatory sensitivity to $\mathrm{CO}_{2}$ and $\mathrm{O}_{2}$

It has been shown in both human (Fan et al. 2010; Xie et al. 2006) and goat (Chapman et al. 1979a) studies that reductions in both basal $\mathrm{CBF}$ and cerebrovascular $\mathrm{CO}_{2}$ reactivity increase the ventilatory responsiveness to hyperoxic hypercapnia, presumably mediated by reduced $\mathrm{H}^{+}$ion washout and associated increase in central chemoreceptor activation. In the present study, INDO-induced reduction in cerebrovascular $\mathrm{CO}_{2}$ reactivity enhanced the ventilatory responsiveness to $\mathrm{CO}_{2}$ during hyperoxic hypercapnia (Fig. 1). Importantly, the INDO-induced increase in the ventilatory $\mathrm{CO}_{2}$ sensitivity in the present study was comparable to those reported by $\mathrm{Xie}$ et al. (2006). Since hyperoxia is known to silence the peripheral chemoreceptor activity in most individuals (Cunningham et al. 1963; Gardner 1980; Mohan and Duffin 1997), we attributed this increase in $\dot{V}_{\mathrm{E}}$ response to hyperoxic hypercapnia associated with INDO to an enhanced central chemoreflex.

An important consideration with regard to the use of INDO to alter ventilatory control is the potential for breathing effects through mechanisms other than at the level of the central chemoreceptors. One hypothesis proposed by Xie et al. (2009) is that INDO may selectively enhance $\dot{V}_{\mathrm{E}}$ by enhancing the peripheral chemoreflex (Xie et al. 2009). As discussed in the introduction, the role of INDO on the peripheral chemoreflex in humans is unclear. 
Xie et al. (2006) reported no difference in the $\dot{V}_{\mathrm{E}}$ response to $\mathrm{CO}_{2}$ under the condition of hyperoxia or normoxia following INDO ingestion $(100 \mathrm{mg})$. From this finding, they proposed that INDO does not influence the peripheral chemoreflex in healthy resting humans. Likewise, Chapman et al. (1979a) found, using carotid artery clamping, that the ventilatory response to transient hypoxia is unaltered with moderate reductions in basal CBF (30\%) and cerebrovascular $\mathrm{CO}_{2}$ reactivity in conscious goats. Consistent with these findings, we did not observe any changes in the $\dot{V}_{\mathrm{E}}$ response to isocapnic hypoxia with INDOinduced reduction in cerebrovascular $\mathrm{CO}_{2}$ reactivity (Fig. 2), thus supporting a preserved peripheral chemoreflex following INDO. Taken together, data from the present study indicate that INDO selectively enhances the central chemoreflex in humans without any concurrent alterations in the peripheral chemoreflex.

Another important consideration is the effect of INDO on cerebral oxygenation. Chapman et al. (1979a) reported a blunted ventilatory response to both hypercapnia and transient hypoxia with severe reductions in CBF (50\%), and near abolishment of cerebrovascular $\mathrm{CO}_{2}$ reactivity blunts the hypoxic ventilatory response. They attributed the latter finding to respiratory neuron depression associated with severe cerebral ischaemia. In the present study, we did not observe a reduction in cerebral oxygenation with INDO administration in healthy adults (Table 1). In contrast, previous studies have shown that INDO-induced reduction in basal CBF lowers cellular oxygenation of brain tissues in both preterm infants with ductus arteriosus (Benders et al. 1995; Lemmers et al. 2008; Liem et al. 1994) and newborn piglets (Yamashita et al. 1999). Whilst the discrepancies between these findings are unclear, it is possible that INDO may have differential effect on cerebral oxygenation between adults and preterm infants. Consistent with this suggestion, during conditions of hypotension (Lucas et al. 2010), exercise (Ainslie et al. 2007) and heat stress (Fan et al. 2008), there have been reports of a maintained cerebral oxygenation despite reductions in MCAv. We acknowledge, however, that since cerebral oxygenation was measured in only seven participants, the effect of INDO on cerebral oxygenation could potentially be masked by insufficient statistical power.

\section{Implications}

An observational study by Xie et al. (2005) demonstrated that congestive heart failure patients with central sleep apnoea display a lower cerebrovascular responsiveness to $\mathrm{CO}_{2}$ compared to patients without central sleep apnoea. Similarly, Reichmuth et al. (2009) found that patients with obstructive sleep apnoea have impaired cerebrovascular function. Recent studies have demonstrated that a single dose of INDO causes breathing instability during wakefulness (Fan et al. 2010), increases the risk of central apnoea (Xie et al. 2009) and augments obstructive sleep apnoea (Burgess et al. 2010). The findings from the present study (Fig. 2) indicate that these INDO-induced increases in breathing instability during both wakefulness and sleep are mediated by its influence on the central chemoreceptor activation, rather than any additional changes in the peripheral chemoreflex. Such findings support the role of a blunted cerebrovascular $\mathrm{CO}_{2}$ reactivity in the pathogenesis of breathing instability.

\section{Conclusion}

Together with previous studies (Bruhn et al. 2001; Eriksson et al. 1983; Fan et al. 2010; Ivancev et al. 2009; Kastrup et al. 1999; Markus et al. 1994; St Lawrence et al. 2002; Wennmalm et al. 1983; Xie et al. 2006, 2009), data from the present study indicate that a single dose of INDO $(100 \mathrm{mg})$ selectively lowers CBF and blunts the cerebrovascular $\mathrm{CO}_{2}$ reactivity without any concurrent changes in the cerebrovascular and ventilatory responses to hypoxia in healthy humans.

Acknowledgments The authors are thankful to Prof. J. Duffin who kindly provided his technical assistance in the rebreathing analysis programme. Special thanks are due to our participants for giving their time for this study. We also extend our thanks to ADInstruments for the use of their laboratory equipment. This study was supported by the Otago Medical Research Foundation, SPARC New Zealand and Peninsula Health Care p/l.

\section{References}

Aaslid R, Markwalder TM, Nornes H (1982) Noninvasive transcranial Doppler ultrasound recording of flow velocity in basal cerebral arteries. J Neurosurg 57:769-774

Ainslie PN, Duffin J (2009) Integration of cerebrovascular $\mathrm{CO}_{2}$ reactivity and chemoreflex control of breathing: mechanisms of regulation, measurement and interpretation. Am J Physiol Regul Integr Comp Physiol 296:R1473-R1495

Ainslie PN, Barach A, Murrell C, Hamlin M, Hellemans J, Ogoh S (2007) Alterations in cerebral autoregulation and cerebral blood flow velocity during acute hypoxia: rest and exercise. Am J Physiol Heart Circ Physiol 292:H976-H983

Al-Rawi PG, Smielewski P, Kirkpatrick PJ (2001) Evaluation of a near-infrared spectrometer (NIRO 300) for the detection of intracranial oxygenation changes in the adult head. Stroke 32:2492-2500

Armstead WM (2000) Altered release of prostaglandins contributes to hypoxic/ischemic impairment of NOC/oFQ cerebrovasodilation. Brain Res 859:104-112

Benders MJ, Dorrepaal CA, van de Bor M, van Bel F (1995) Acute effects of indomethacin on cerebral hemodynamics and oxygenation. Biol Neonate 68:91-99 
Bishop CC, Powell S, Rutt D, Browse NL (1986) Transcranial Doppler measurement of middle cerebral artery blood flow velocity: a validation study. Stroke 17:913-915

Blain GM, Smith CA, Henderson KS, Dempsey JA (2009) Contribution of the carotid body chemoreceptors to eupneic ventilation in the intact, unanesthetized dog. J Appl Physiol 106:1564-1573

Brian JE Jr, Moore SA, Faraci FM (1998) Expression and vascular effects of cyclooxygenase-2 in brain. Stroke 29:2600-2606

Bruhn H, Fransson P, Frahm J (2001) Modulation of cerebral blood oxygenation by indomethacin: MRI at rest and functional brain activation. J Magn Reson Imaging 13:325-334

Burgess KR, Fan JL, Peebles K, Thomas K, Lucas S, Lucas R, Dawson A, Swart M, Shepherd K, Ainslie P (2010) Exacerbation of obstructive sleep apnea by oral indomethacin. Chest 137: $707-710$

Chapman RW, Santiago TV, Edelman NH (1979a) Effects of graded reduction of brain blood flow on chemical control of breathing. J Appl Physiol 47:1289-1294

Chapman RW, Santiago TV, Edelman NH (1979b) Effects of graded reduction of brain blood flow on ventilation in unanesthetized goats. J Appl Physiol 47:104-111

Claassen JA, Zhang R, Fu Q, Witkowski S, Levine BD (2007) Transcranial Doppler estimation of cerebral blood flow and cerebrovascular conductance during modified rebreathing. J Appl Physiol 102:870-877

Coyle MG, Oh W, Stonestreet BS (1993) Effects of indomethacin on brain blood flow and cerebral metabolism in hypoxic newborn piglets. Am J Physiol 264:H141-H149

Coyle MG, Oh W, Petersson KH, Stonestreet BS (1995) Effects of indomethacin on brain blood flow, cerebral metabolism, and sagittal sinus prostanoids after hypoxia. Am J Physiol 269: H1450-H1459

Cunningham DJ, Hey EN, Patrick JM, Lloyd BB (1963) The effect of noradrenaline infusion on the relation between pulmonary ventilation and the alveolar $\mathrm{PO}_{2}$ and $\mathrm{PCO}_{2}$ in man. Ann N Y Acad Sci 109:756-771

Dahan A, Sarton E, Teppema L (2008) Plasticity in the brain: influence of bilateral carotid body resection (bCBR) on central $\mathrm{CO}_{2}$ sensitivity. Adv Exp Med Biol 605:312-316

Day TA, Wilson RJ (2009) A negative interaction between brainstem and peripheral respiratory chemoreceptors modulates peripheral chemoreflex magnitude. J Physiol 587:883-896

Docherty JC, Wilson TW (1987) Indomethacin increases the formation of lipoxygenase products in calcium ionophore stimulated human neutrophils. Biochem Biophys Res Commun 148:534-538

Eriksson S, Hagenfeldt L, Law D, Patrono C, Pinca E, Wennmalm A (1983) Effect of prostaglandin synthesis inhibitors on basal and carbon dioxide stimulated cerebral blood flow in man. Acta Physiol Scand 117:203-211

Fan JL, Cotter JD, Lucas RA, Thomas K, Wilson L, Ainslie PN (2008) Human cardiorespiratory and cerebrovascular function during severe passive hyperthermia: effects of mild hypohydration. J Appl Physiol 105:433-445

Fan JL, Burgess KR, Thomas KN, Peebles KC, Lucas SJ, Lucas RA, Cotter JD, Ainslie PN (2010) Influence of indomethacin on ventilatory and cerebrovascular responsiveness to $\mathrm{CO}_{2}$ and breathing stability: the influence of $\mathrm{PCO}_{2}$ gradients. Am J Physiol Regul Integr Comp Physiol 298:R1648-R1658

Fencl V (1986) Acid-base balance in cerebral fluids. In: Fishman AP, Cherniack NS, Widdicombe JG, Geiger SR (eds) Handbook of physiology. Section 3, The respiratory system. American Physiological Society, Bethesda

Gardner WN (1980) The pattern of breathing following step changes of alveolar partial pressures of carbon dioxide and oxygen in man. J Physiol 300:55-73
Giller CA, Bowman G, Dyer H, Mootz L, Krippner W (1993) Cerebral arterial diameters during changes in blood pressure and carbon dioxide during craniotomy. Neurosurgery 32:737-741 (discussion 741-742)

Gomez-Nino A, Almaraz L, Gonzalez C (1992) Potentiation by cyclooxygenase inhibitors of the release of catecholamines from the rabbit carotid body and its reversal by prostaglandin E2. Neurosci Lett 140:1-4

Gomez-Nino A, Almaraz L, Gonzalez C (1994) In vitro activation of cyclo-oxygenase in the rabbit carotid body: effect of its blockade on [3H]catecholamine release. J Physiol 476:257-267

Green RS, Leffler CW, Busija DW, Fletcher AM, Beasley DG (1987) Indomethacin does not alter the circulating catecholamine response to asphyxia in the neonatal piglet. Pediatr Res 21: $534-537$

Hohimer AR, Richardson BS, Bissonnette JM, Machida CM (1985) The effect of indomethacin on breathing movements and cerebral blood flow and metabolism in the fetal sheep. J Dev Physiol 7:217-228

Hsu P, Shibata M, Leffler CW (1993) Prostanoid synthesis in response to high $\mathrm{CO}_{2}$ in newborn pig brain microvascular endothelial cells. Am J Physiol 264:H1485-H1492

Isozumi K, Fukuuchi Y, Takeda H, Itoh Y (1994) Mechanisms of $\mathrm{CBF}$ augmentation during hypoxia in cats: probable participation of prostacyclin, nitric oxide and adenosine. Keio J Med 43:31-36

Ivancev V, Bakovic D, Obad A, Breskovic T, Palada I, Joyner MJ, Dujic Z (2009) Effects of indomethacin on cerebrovascular response to hypercapnea and hypocapnea in breath-hold diving and obstructive sleep apnea. Respir Physiol Neurobiol 166: $152-158$

Jansen AH, De Boeck C, Ioffe S, Chernick V (1984) Indomethacininduced fetal breathing: mechanism and site of action. J Appl Physiol 57:360-365

Jensen K, Kjaergaard S, Malte E, Bunemann L, Therkelsen K, Knudsen F (1996) Effect of graduated intravenous and standard rectal doses of indomethacin on cerebral blood flow in healthy volunteers. J Neurosurg Anesthesiol 8:111-116

Kastrup A, Happe V, Hartmann C, Schabet M (1999) Gender-related effects of indomethacin on cerebrovascular $\mathrm{CO}_{2}$ reactivity. J Neurol Sci 162:127-132

Konig W, Brom J, Schonfeld W, Knoller J, Stuning M (1987) Effect of tenoxicam and indomethacin on the release of histamine, prostaglandin E2 and leukotrienes from various cells. Arzneimittelforschung 37:296-299

Kraaier V, Van Huffelen AC, Wieneke GH, Van der Worp HB, Bar PR (1992) Quantitative EEG changes due to cerebral vasoconstriction. Indomethacin versus hyperventilation-induced reduction in cerebral blood flow in normal subjects. Electroencephalogr Clin Neurophysiol 82:208-212

Leffler CW, Parfenova H (1997) Cerebral arteriolar dilation to hypoxia: role of prostanoids. Am J Physiol 272:H418-H424

Lemmers PM, Toet MC, van Bel F (2008) Impact of patent ductus arteriosus and subsequent therapy with indomethacin on cerebral oxygenation in preterm infants. Pediatrics 121:142-147

Liem KD, Hopman JC, Kollee LA, Oeseburg B (1994) Effects of repeated indomethacin administration on cerebral oxygenation and haemodynamics in preterm infants: combined near infrared spectrophotometry and Doppler ultrasound study. Eur J Pediatr 153:504-509

Lucas SJ, Tzeng YC, Galvin SD, Thomas KN, Ogoh S, Ainslie PN (2010) Influence of changes in blood pressure on cerebral perfusion and oxygenation. Hypertension 55:698-705

Markus HS, Vallance P, Brown MM (1994) Differential effect of three cyclooxygenase inhibitors on human cerebral blood flow velocity and carbon dioxide reactivity. Stroke 25:1760-1764 
McCalden TA, Nath RG, Thiele K (1984) The role of prostacyclin in the hypercapnic and hypoxic cerebrovascular dilations. Life Sci 34:1801-1807

McQueen DS, Belmonte C (1974) The effects of prostaglandins E2, A2 and F2 alpha on carotid baroreceptors and chemoreceptors. Q J Exp Physiol Cogn Med Sci 59:63-71

Mohan R, Duffin J (1997) The effect of hypoxia on the ventilatory response to carbon dioxide in man. Respir Physiol 108:101-115

Mohan RM, Amara CE, Cunningham DA, Duffin J (1999) Measuring central-chemoreflex sensitivity in man: rebreathing and steadystate methods compared. Respir Physiol 115:23-33

Mollace V, Muscoli C, Rotiroti D, Nistico G (1997) Spontaneous induction of nitric oxide- and prostaglandin E2-release by hypoxic astroglial cells is modulated by interleukin 1 beta. Biochem Biophys Res Commun 238:916-919

Nishimura M, Suzuki A, Nishiura Y, Yamamoto H, Miyamoto K, Kishi F, Kawakami Y (1987) Effect of brain blood flow on hypoxic ventilatory response in humans. J Appl Physiol 63:1100-1106

Nollert G, Mohnle P, Tassani-Prell P, Reichart B (1995) Determinants of cerebral oxygenation during cardiac surgery. Circulation 92:II327-II333

Northover BJ (1977) Effect of indomethacin and related drugs on the calcium ion-dependent secretion of lysosomal and other enzymes by neutrophil polymorphonuclear leucocytes in vitro. $\mathrm{Br} \mathrm{J}$ Pharmacol 59:253-259

Noth U, Kotajima F, Deichmann R, Turner R, Corfield DR (2008) Mapping of the cerebral vascular response to hypoxia and hypercapnia using quantitative perfusion MRI at $3 \mathrm{~T}$. NMR Biomed 21:464-472

Nuttall GA, Cook DJ, Fulgham JR, Oliver WC Jr, Proper JA (1996) The relationship between cerebral blood flow and transcranial Doppler blood flow velocity during hypothermic cardiopulmonary bypass in adults. Anesth Analg 82:1146-1151

Pandit JJ, Mohan RM, Paterson ND, Poulin MJ (2007) Cerebral blood flow sensitivities to $\mathrm{CO}_{2}$ measured with steady-state and modified rebreathing methods. Respir Physiol Neurobiol 159: $34-44$

Parfenova H, Leffler CW (1996) Effects of hypercapnia on prostanoid and cAMP production by cerebral microvascular cell cultures. Am J Physiol 270:C1503-C1510

Parfenova H, Shibata M, Zuckerman S, Leffler CW (1994) $\mathrm{CO}_{2}$ and cerebral circulation in newborn pigs: cyclic nucleotides and prostanoids in vascular regulation. Am J Physiol 266:H1494H1501

Parfenova H, Hsu P, Leffler CW (1995a) Dilator prostanoid-induced cyclic AMP formation and release by cerebral microvascular smooth muscle cells: inhibition by indomethacin. J Pharmacol Exp Ther 272:44-52

Parfenova H, Zuckerman S, Leffler CW (1995b) Inhibitory effect of indomethacin on prostacyclin receptor-mediated cerebral vascular responses. Am J Physiol 268:H1884-H1890

Peebles KC, Richards AM, Celi L, McGrattan K, Murrell CJ, Ainslie PN (2008) Human cerebral arteriovenous vasoactive exchange during alterations in arterial blood gases. J Appl Physiol 105:1060-1068

Pickard J, Tamura A, Stewart M, McGeorge A, Fitch W (1980) Prostacyclin, indomethacin and the cerebral circulation. Brain Res 197:425-431

Pickles H, Brown MM, Thomas M, Hewazy AH, Redmond S, Zilkha E, Marshall J (1984) Effect of indomethacin on cerebral blood flow, carbon dioxide reactivity and the response to epoprostenol (prostacyclin) infusion in man. J Neurol Neurosurg Psychiatry 47:51-55

Pourcyrous M, Leffler CW, Bada HS, Korones SB, Busija DW (1993) Brain superoxide anion generation in asphyxiated piglets and the effect of indomethacin at therapeutic dose. Pediatr Res 34:366-369

Reichmuth KJ, Dopp JM, Barczi SR, Skatrud JB, Wojdyla P, Hayes D Jr, Morgan BJ (2009) Impaired vascular regulation in patients with obstructive sleep apnea: effects of CPAP treatment. Am J Respir Crit Care Med 180(11):1143-1150

Serrador JM, Picot PA, Rutt BK, Shoemaker JK, Bondar RL (2000) MRI measures of middle cerebral artery diameter in conscious humans during simulated orthostasis. Stroke 31:1672-1678

Severinghaus JW (1979) Simple, accurate equations for human blood $\mathrm{O}_{2}$ dissociation computations. J Appl Physiol 46:599-602

St Lawrence KS, Ye FQ, Lewis BK, Weinberger DR, Frank JA, McLaughlin AC (2002) Effects of indomethacin on cerebral blood flow at rest and during hypercapnia: an arterial spin tagging study in humans. J Magn Reson Imaging 15:628-635

Staessen J, Cattaert A, Fagard R, Lijnen P, Moerman E, De Schaepdryver A, Amery A (1984) Hemodynamic and humoral effects of prostaglandin inhibition in exercising humans. J Appl Physiol 56:39-45

ter Minassian A, Melon E, Leguerinel C, Lodi CA, Bonnet F, Beydon $\mathrm{L}$ (1998) Changes in cerebral blood flow during $\mathrm{PaCO}_{2}$ variations in patients with severe closed head injury: comparison between the Fick and transcranial Doppler methods. J Neurosurg 88:996-1001

Therkelsen K, Jensen KA, Freundlich M, Thorshauge H, Bunemann L, Bogeskov Nielsen L (1994) Endothelin-1 and cerebral blood flow: influence of hypoxia, hypercapnia and indomethacin on circulating endothelin levels in healthy volunteers. Scand J Clin Lab Invest 54:441-451

Valdueza JM, Balzer JO, Villringer A, Vogl TJ, Kutter R, Einhaupl KM (1997) Changes in blood flow velocity and diameter of the middle cerebral artery during hyperventilation: assessment with MR and transcranial Doppler sonography. Ajnr 18:1929-1934

van Bel F, Sola A, Roman C, Rudolph AM (1997) Perinatal regulation of the cerebral circulation: role of nitric oxide and prostaglandins. Pediatr Res 42:299-304

Wagerle LC, Degiulio PA (1994) Indomethacin-sensitive $\mathrm{CO}_{2}$ reactivity of cerebral arterioles is restored by vasodilator prostaglandin. Am J Physiol 266:H1332-H1338

Wang Q, Paulson OB, Lassen NA (1993) Indomethacin abolishes cerebral blood flow increase in response to acetazolamideinduced extracellular acidosis: a mechanism for its effect on hypercapnia? J Cereb Blood Flow Metab 13:724-727

Wennmalm A, Eriksson S, Hagenfeldt L, Law D, Patrono C, Pinca E (1983) Effect of prostaglandin synthesis inhibitors on basal and carbon dioxide-stimulated cerebral blood flow in man. Adv Prostaglandin Thromboxane Leukot Res 12:351-355

Wennmalm A, Carlsson I, Edlund A, Eriksson S, Kaijser L, Nowak J (1984) Central and peripheral haemodynamic effects of nonsteroidal anti-inflammatory drugs in man. Arch Toxicol Suppl $7: 350-359$

Xie A, Skatrud JB, Khayat R, Dempsey JA, Morgan B, Russell D (2005) Cerebrovascular response to carbon dioxide in patients with congestive heart failure. Am J Respir Crit Care Med 172:371-378

Xie A, Skatrud JB, Morgan B, Chenuel B, Khayat R, Reichmuth K, Lin J, Dempsey JA (2006) Influence of cerebrovascular function on the hypercapnic ventilatory response in healthy humans. J Physiol 577:319-329

Xie A, Skatrud JB, Barczi SR, Reichmuth K, Morgan BJ, Mont S, Dempsey JA (2009) Influence of cerebral blood flow on breathing stability. J Appl Physiol 106:850-856

Yamashita Y, Murakami Y, Wada N, Togo A, Matsuishi T, Kato H (1999) Effects of indomethacin and hyperventilation on cerebral hemodynamics and oxygenation in newborn piglets. Kurume Med J 46:137-141 